\title{
Harvest Pressures Affect Forced Summer Asparagus Yield in Coastal South Carolina
}

\author{
Robert J. Dufault' \\ Coastal Research and Education Center, Department of Horticulture, Clemson University, 2865 Savannah \\ Highway, Charleston, SC 29414 \\ Additional index words. Asparagus officinalis, crown, stands, cutting pressure
}

\begin{abstract}
The purpose of this study was to investigate the effect of different cutting pressures (CP) of 3,6,9, or 12 spears per plant on ' $U C 157 F_{1}$ ' asparagus yield harvested in spring or forced in July or August. Ten-week-old seedlings were field planted in March, 1987 and forced to emerge from 1989 to 1993 by mowing fern in separate replicated plots in July or August. Forcing treatments were not spring-harvested. Harvesting was terminated if 1) 30 harvests had occurred or 2) $80 \%$ of all plants reached cutting pressure treatment levels before 30 harvests occurred. Forced yields were compared to normal spring harvests. Normal emergence time is from January to March. CP treatments affected yield more than harvest time (HT) during the first three harvest years, but, thereafter, HT treatments affected yield more than CP. The most productive HT/CP treatment combinations varied by harvest year as follows: 1989 — spring at 9 to 12 spears per plant, July at 12 spears per plant, and August at 9 spears per plant; 1990 - forcing in July or August at 12 spears per plant; 1991 - forcing in July at 9 to 12 spears per plant; 1992 - forcing in July or August at 9 to 12 spears; and 1993 -forcing in August at 9 to 12 spears per plant. Total cumulative yields over the 5 year period were highest with forcing in July at 12 spears per plant and August at 9 spears per plant. The productive lifespan of spring-harvested ' $U C$ C $157 F_{1}$ ' was only three years because of greater stand loss compared to summer forcing.
\end{abstract}

Domestic production of asparagus in the United States occurs from about January to late June. From July to December, fresh asparagus is imported into the United States. If asparagus could be forced out of season in areas with subtropical climates, such as coastal South Carolina, some of this market may be captured during midsummer to early fall.

Summer forcing of asparagus has been attempted in Mississippi (Farish, 1937), central South Carolina (Scott et al., 1939), Delaware (Brasher, 1956), Canada (Jasmin and Laliberte, 1962), and Mexico (Campbell Institute for Agricultural Research, 1970). These studies indicated that forcing has potential only in areas with long growing seasons in southern latitudes. In Taiwan, asparagus is customarily harvested in spring and then forced in summer and fall (Lib Hung, National Taiwan Univ., personal communication). Recently, Dufault (1994a and 1994b) reported that forcing 'UC $157 \mathrm{~F}_{1}$ ' asparagus from July through September in coastal South Carolina produced acceptable yields over a 5-year harvest period. Spring yields progressively declined over a 5-year duration. Cooler temperatures during spring harvest season prevent the plants from producing the desired cutting pressure of eight spears per plant within a 6-week harvest season. Warmer temperatures during summer forcing caused the majority of plants to reach the desired cutting pressure level within a standard 8-week harvest season.

The length of the harvest season to produce the greatest yields is an important consideration in asparagus production. Previous work indicated that a 7 to 9 week harvest season in the spring was most desirable (Deonier and Hoffman, 1944; Haber, 1935; Jones, 1932; Takatori et al., 1970; Williams and Garthwaite, 1973). Excessive extension of the harvest season, however, may increase the severity of carbohydrate depletion, reduce the recovery period after harvest, and reduce plant vigor. Williams and Garthwaite

Received for publication 19 Apr. 1994. Accepted for publication 2 Aug. 1994. Technical contribution no. 3589 of the South Carolina Agricultural Experiment Station, Clemson Univ. The cost of publishing this paper was defrayed in part by payment of page charges. Under postal regulations, this paper therefore must be hereby marked advertisement solely to indicate this fact.

'Associate professor.
(1973) found that increasing the harvest season from 2 to 4 weeks increased yield in the first 2 years of production, but reduced yields from the third to fifth years. Shelton and Lacy (1980) found that harvesting for 4 to 6 weeks in the second year after transplanting crowns and 8 to 10 weeks the following year reduced yields significantly in the fourth year after transplanting. Extension of the harvest season decreased spear size and crown carbohydrates.

The purpose of this study was to investigate the effect of different cutting pressures on asparagus yield harvested in spring and forced in July and August and to determine an appropriate cutting pressure for spring and summer production.

\section{Methods and Materials}

On 24 Mar. 1987, 10-week-old ' $\mathrm{UC} 157 \mathrm{~F}_{1}$ ' asparagus seedlings were transplanted in the bottom of $10 \mathrm{~cm}$ deep furrows $30 \mathrm{~cm}$ apart within double rows. Each double row plot, or bed, was $6 \mathrm{~m}$ long, $1.8 \mathrm{~m}$ apart from bed center, and contained 40 transplants. The soil was a Yauhannah loamy fine sand (Aquic Hapludults). Each plot consisted of double test rows within a bed and was bordered on each side by double guard rows. In 1988, the soil was ridged approximately $20 \mathrm{~cm}$ over the normal ground level before spear emergence and maintained at that height for 5 years. Standard commercial cultural practices were used during the course of the experiment (Cook, 1986).

The experiment was a factorial combination of two factors: 1) harvest time (HT)—normal spring emergence occurring from January to March and forcing in July or August and 2) cutting pressures $(\mathrm{CP})$ of $3,6,9$, or 12 spears per plant. The HT and $\mathrm{CP}$ experimental treatments were replicated four times in a randomized block design.

Forcing plots were allowed to produce fern in the spring without any harvests. To force spears, all fern and stalks within the test and guard plots were cut to the ground during the first week of each forcing month. Plant stands within each plot were counted in spring each year about one month after first spear emergence.

Asparagus spears were harvested by cutting above the soil 

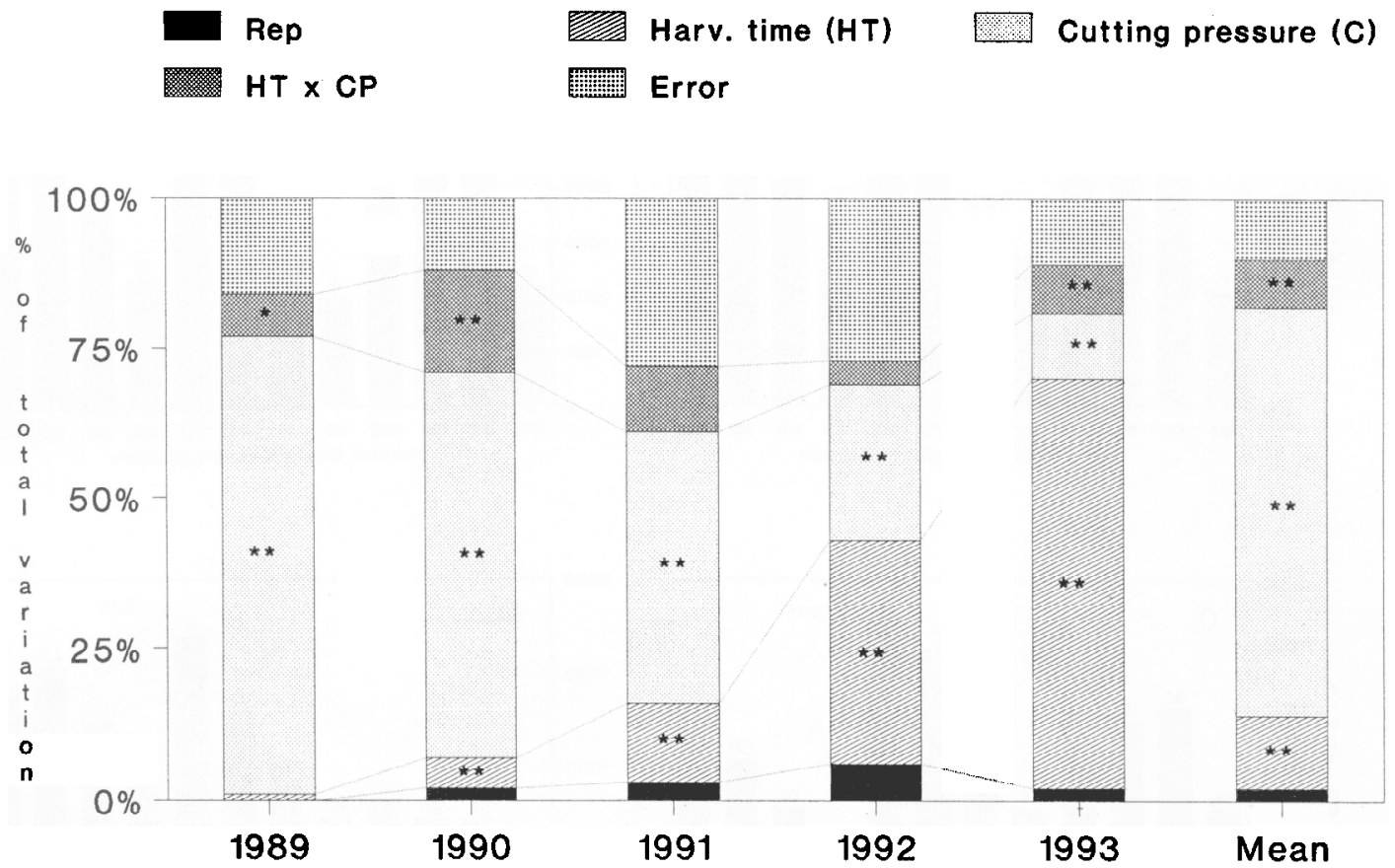

Fig. 1. Total variation from 1989 to 1993 in marketable yield due to sources of variation in the ANOVA. Sum of squares for each factor converted to a percentage of total sum of squares and $\mathrm{F}$ test significant at $P=0.05(*)$ and $0.01(* *)$.

surface with a knife and then brightly painted wooden markers were inserted into the soil next to cut stumps. Wooden markers were counted each harvest day and allowed easy accounting of actual $\mathrm{CP} /$ plant. Harvests for individual plots were terminated if either 1) 30 harvests occurred for that plot or 2) $80 \%$ of the plants within each plot reached the CP treatment level before 30 harvests occurred. At the end of the harvest season, the number of plants that did not achieve the prescribed CP treatment level within 30 harvests was counted. This variable was defined as a plants' ability to reach a prescribed CP treatment level. The inability of a plant to produce the prescribed $\mathrm{CP}$ treatment level before the termination of the harvest season indicated dwindling vigor affecting recovery and yield in subsequent years.

Asparagus was graded into either marketable or cull quality categories based on U.S. Dept. of Agriculture (USDA) standards (USDA, 1977). Diameter of each marketable spear butt was measured and graded as jumbo $(>1.3 \mathrm{~cm})$, medium $(0.8$ to $1.3 \mathrm{~cm})$, or small $(<0.8 \mathrm{~cm})$.

The data were subjected to ANOVA and means separated by LSD if the $\mathrm{F}$ test was significant at $P=0.05$. The relative importance of HT and CP treatment effects and their interaction were determined by partitioning the total sum of squares for treatments into main and interaction effects and expressing these individual contributions to variation as a percentage of the sum of squares for the model (composed of only those sources of variation in the ANOVA). These data provided an index of the relative effectiveness, importance and dynamic changes in all treatment main effects, interactions and replication effects, and uncontrolled error during each harvest year over the experiment's 5 year harvest lifespan.

\section{Results}

Yield vs. CP and HT. First spring spear emergence varied yearly and occurred on 18 Jan. 1989,26 Jan. 1990,4 Mar. 1991,26 Feb. 1992, and 26 Mar. 1993. The relative importance of CP and HT treatments and their interaction changed over the 5-year period with $\mathrm{CP}$ affecting yield more than HT in the first 3 harvest years, but HT becoming more important in the fourth and fifth years (Fig. 1). Seventy-six percent of the variation in 1989 marketable yield was assigned to the effect of $\mathrm{CP}$, but progressively diminished to $64 \%, 45 \%, 26 \%$, and $11 \%$ in 1990, 1991, 1992, and 1993, respectively. The influence of HT was negligible in 1989, but gradually increased from 1990 to 1991 becoming the major source of variation in yield in 1992 and 1993 accounting for 37\% and 68\% of all variation, respectively. $\mathrm{CP}$ was the dominant factor affecting total cumulative marketable yield (summed over 1989 to 1993), contributing $68 \%$ of the variation with HT contributing only $12 \%$.

The ranking of the most productive $\mathrm{HT}$ and $\mathrm{CP}$ combinations varied by harvest year. In 1989, yields were greatest and equivalent for the following treatment combinations: spring at CPs of 9 and 12 spears per plant, July at 12 spears per plant, and August at 9 spears per plant (Fig. 2A). Spring and August yields increased as $\mathrm{CP}$ increased from 3 to 9 spears per plant but not at a CP of 12 spears per plant. July yields increased progressively as CP increased from 3 to 12 spears per plant. In 1990, yields increased in July and August forcings as CP increased from 3 to 12 spears per plant (Fig. 2B). Spring yields were lower with a $\mathrm{CP}$ of 3 spears per plant than at CPS of 6 to 12 spears per plant. Spring yields for CPS ranging from 6 to 12 spears per plant were similar. In 1991, forcing in July at 12 spears per plant yielded more than harvesting in spring or August at any CP (Fig. 2C). Although lower than July forcing at 12 spears per plant, yields were equivalent for the following: forcing in August at 12 spears per plant, July forcing at 9 spears per plant and spring harvests from 6 to 12 spears per plant. Spring yields in 1992 were very low and similar at all CPS (Fig. 2D). Yields from July or August forcing increased as CP increased from 3 to 9 spears per plant without any advantage for harvesting at a CP of 12 spears per plant. In 1993, the final harvest year, spring yields were very poor and increasing $\mathrm{CP}$ from 3 to 12 spears per plant did not improve productivity y (Fig. 2E). August forcing yields increased as $\mathrm{CP}$ increased from 3 to 9 spears per plant without further increases with a CP of 12 spears per plant. July forcing yields increased with CPS increasing from 3 to 9 spears per plant without further effect at 12 spears per plant. 

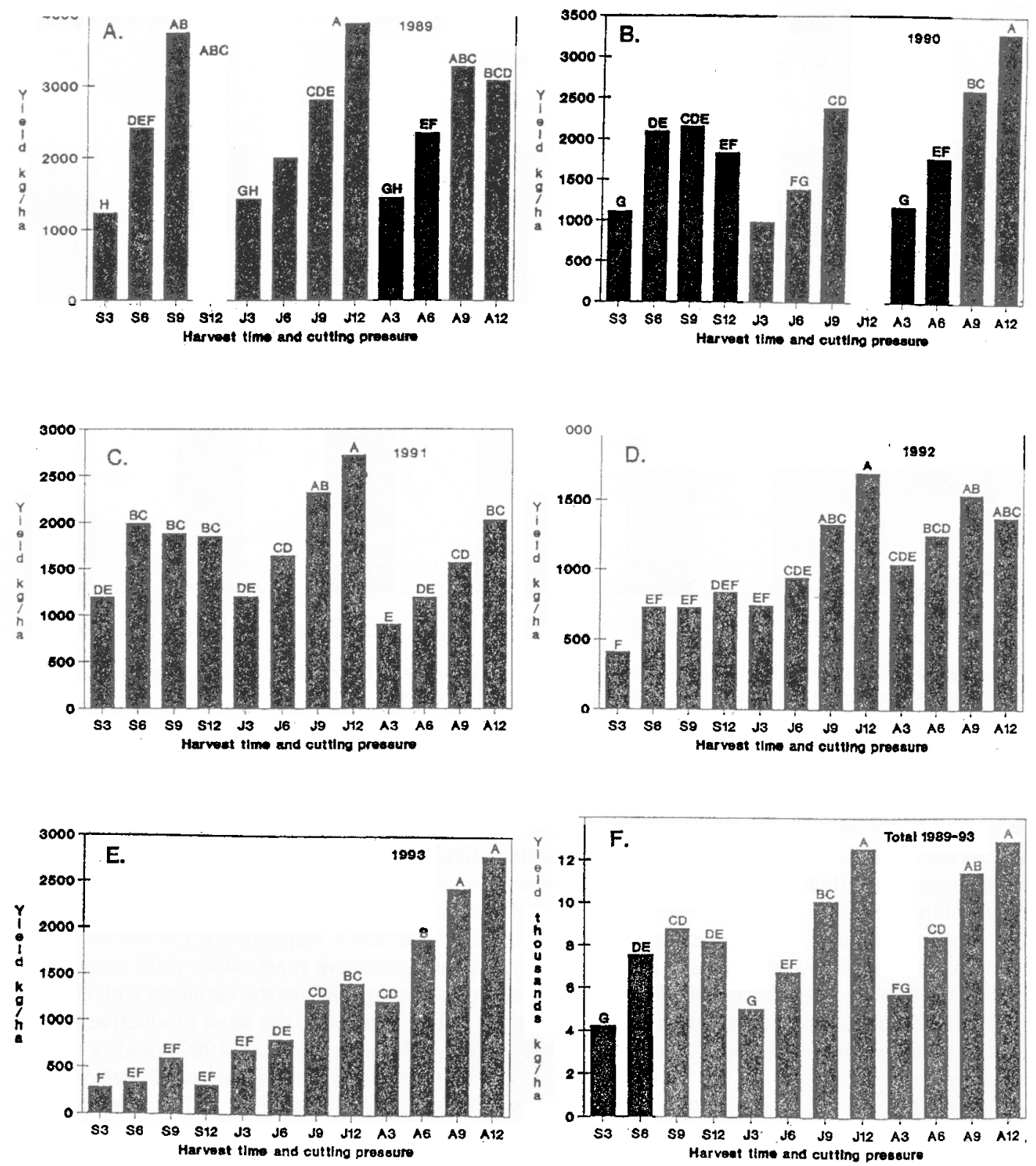

Fig. 2. Influence of harvest time and cutting pressure on marketable yield in 1989 (A), 1990 (B), 1991 (C), 1992 (D), 1993 (E), and the total cumulative yield from 1989 to 1993 (F). Bars within each year with different letters are significant by LSD, $P=0.05$.

Yields from 5 years were summed to determine which HT/CP treatment combinations showed the best potential for overall high yields (Fig. 2F). The most production combinations were forcing in July at 12 spears per plant and August at 9 spears per plant. Although spring yields were poor over the 5-year period, a CP of no more than 6 spears per plant produced the greatest yields within that harvest season.

Quality vs. CP and HT. Production of jumbo diameter spears is an indicator of higher quality and plant vigor and, conversely, small diameter spears indicate lower quality and plant vigor. Although the majority of variation in small and jumbo spears from 1989 to 1991 was due to an uncontrolled error. It was of interest to determine the relative importance of $\mathrm{HT}$ and $\mathrm{CP}$ treatments on small and jumbo production over harvest years (Fig. 3). In 1989, $22 \%$ of the variation in jumbo production was assigned to HT with CP contributing only 8\%. From 1990 to 1992, HT and CP contributed on average about $17 \%$ and $15 \%$ each to total variation, respectively. By 1993, however, HT became the dominant factor affecting jumbo production accounting for $62 \%$ of all variation, but $\mathrm{CP}$, in contrast, contributed only $7 \%$.

From 1989 to 1990 , both CP and HT contributed to the variation in small spear production, averaging $31 \%$ and $24 \%$, respectively. In 1991, CP contributed $34 \%$ of all variation with negligible amounts assigned to HT treatments. In 1992, neither CP nor HT affected small spear production. By 1993, HT contributed $66 \%$ of all variation in spears with only $6 \%$ assigned to the effect of $\mathrm{CP}$.

In the first harvest year, spring harvests yielded more jumbo spears but fewer small spears than summer forcing in July or August (Fig. 4A). In 1990, July and August forcings yielded more jumbo and fewer small spears than spring harvesting. HT did not affect small spear production from 1991 to 1992, but jumbo production in 1991 was greater with July forcing than with either spring or August harvests. Forcing in July and August, 1992, yielded more jumbo spears than spring harvesting. By the final 


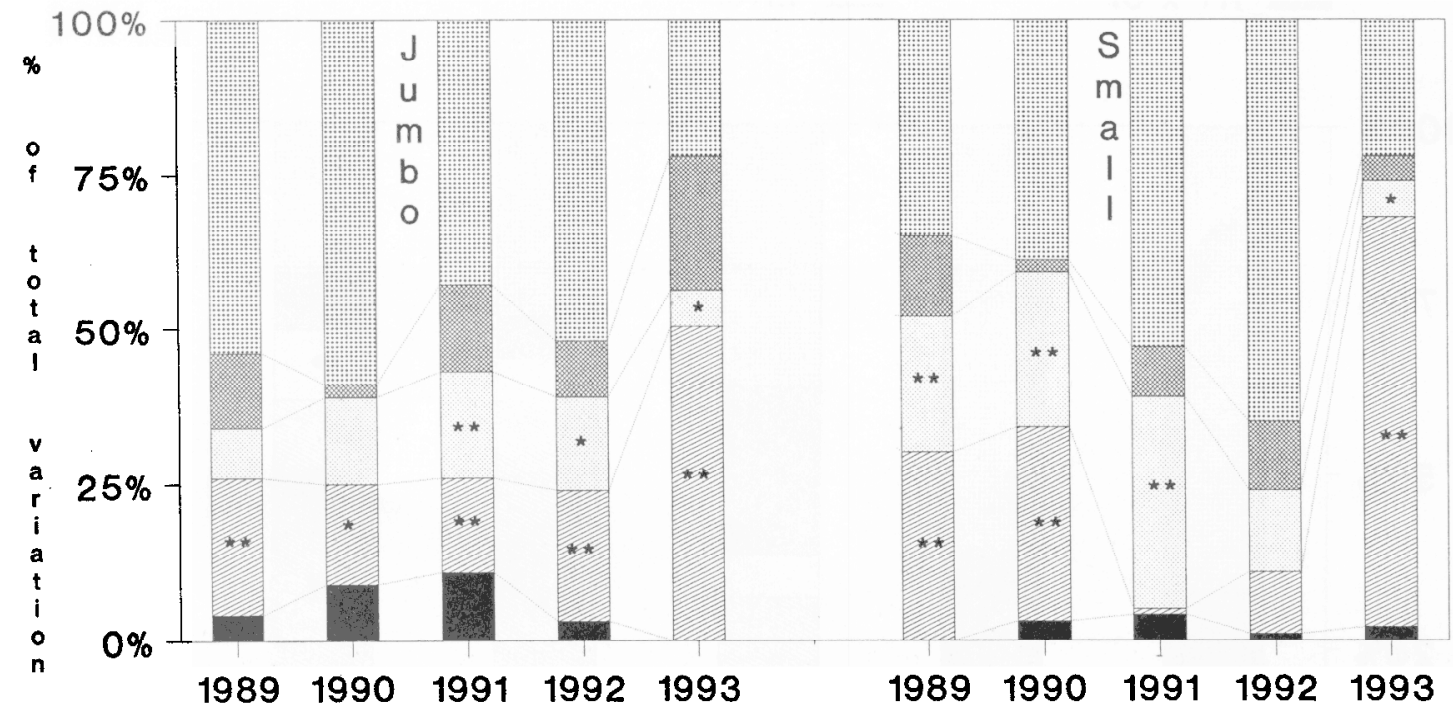

Fig. 3. Total variation from 1989 to 1993 in jumbo (butt diameter $>1.3 \mathrm{~cm}$ ) or small (butt diameter $<0.8 \mathrm{~cm}$ ) spear production due to sources of variation in the ANOVA. Sum of squares for each factor converted to a percentage of total sum of squares and $\mathrm{F}$ test significant at $P=0.05(*)$ and $0.01(* *)$.
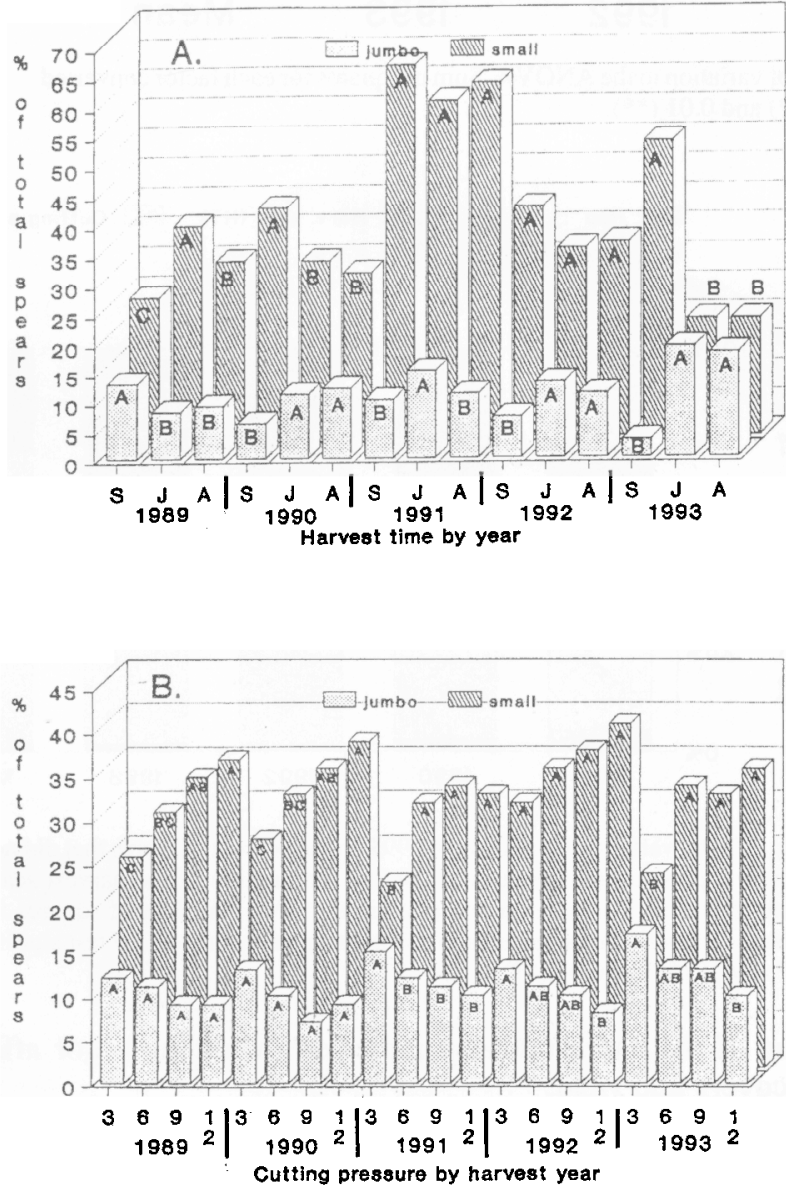

Fig. 4. Influence of harvest time (A) and cutting pressure (B) on jumbo and small diameter spear production from 1989 to 1993. Mean separation is within each year and bars with different letters arc significant by LSD, $P=0.05$. $\mathrm{S}=$ spring, $\mathrm{J}$ $=$ July, $\mathrm{A}=$ August, followed by number of harvested spears per plant. harvest year, over $50 \%$ of all spring-harvested spears were small but only $20 \%$ were classified as small in either July or August forcings.

$\mathrm{CP}$ and HT did not interact in any harvest year to affect jumbo or small spear production (Fig. 3). The main effect of $\mathrm{CP}$, therefore, describes the influence of $\mathrm{CP}$ treatment levels in all harvest times. Cutting pressure severity affected jumbo spear production significantly for the first time beginning in the third harvest year (Fig. 4B). In 1991, a CP of 3 spears per plant produced more jumbo spears, but the number of jumbo spears was the same for CPS of 6 to 12 spears per plant. During 1992 and 1993, jumbo production was similar at CPS of 3 to 9 spears per plant, but increasing the CP to 12 spears per plant decreased jumbo's in contrast to a $\mathrm{CP}$ of 3 spears per plant. During 1989 to 1990 , increasing the CP from 3 to 12 spears per plant increased the production of small spears. In 1991 and 1993, fewer small spears were produced at a CP of 3 spears per plant than at 6 to 12 spears per plant. In 1992, CP severity did not affect small spear production.

Stand vs. CP and HT. The inability of asparagus to recover from harvest stresses as a result of $\mathrm{HT}$ and $\mathrm{CP}$ treatments is partially indicated by the decline in plant populations over harvest years. The stands for all field plots were similar from 1987 to 1990 and were not affected by HT and CP treatments until 1991. In 1991, similar amounts of variation in stand loss were contributed by HT and CP treatments, but from 1992 to 1993, HT contributed the majority of variation to stand loss than CP (Fig. 5). Analysis of the total loss of plants from 1989 to 1993 indicated that HT accounted for $58 \%$ of all variation in stand loss and that only 9\% was attributed to $\mathrm{CP}$ treatments.

The first significant effect of harvest time on reducing stands began in 1991 in spring-harvested plots (Fig. 6). From 1992 to 1993, stands in the spring-harvested plots continued to rapidly decline and stands in the July-forced plots began to decrease more in contrast to August-forced plots. By the last harvest year, 60\%, $43 \%$ and $29 \%$ of all plants died during the period from 1988 to 1993 in the spring, July and August harvested plots, respectively.

The main effect of CP did not affect stand loss during any of the 


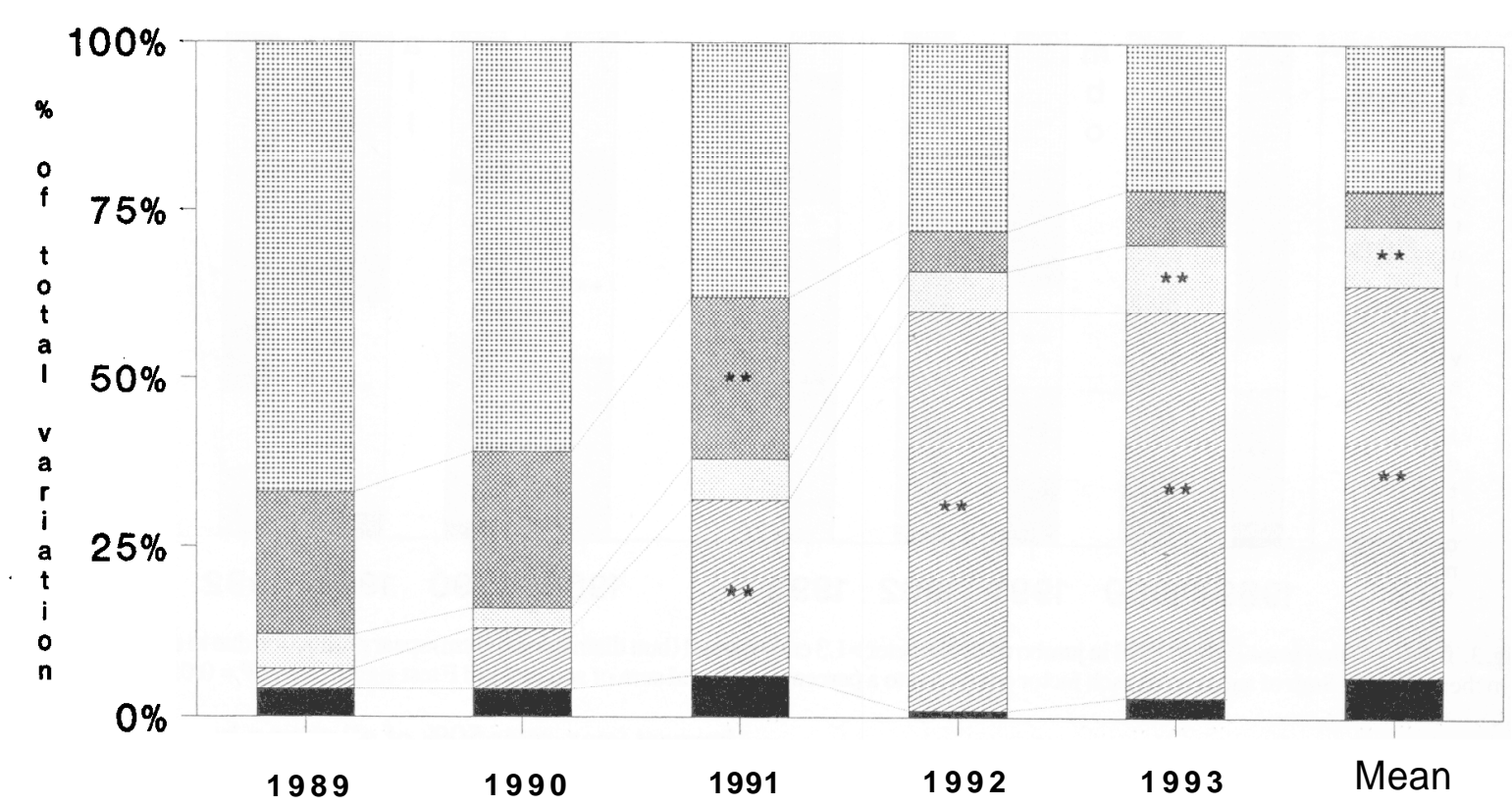

Fig. 5. Total variation from 1989 to 1993 on loss in plant stand due to sources of variation in the ANOVA. Sum of squares for each factor converted to a percentage of total sum of squares and $\mathrm{F}$ test significant at $P=0.05(*)$ and $0.01(* *)$.

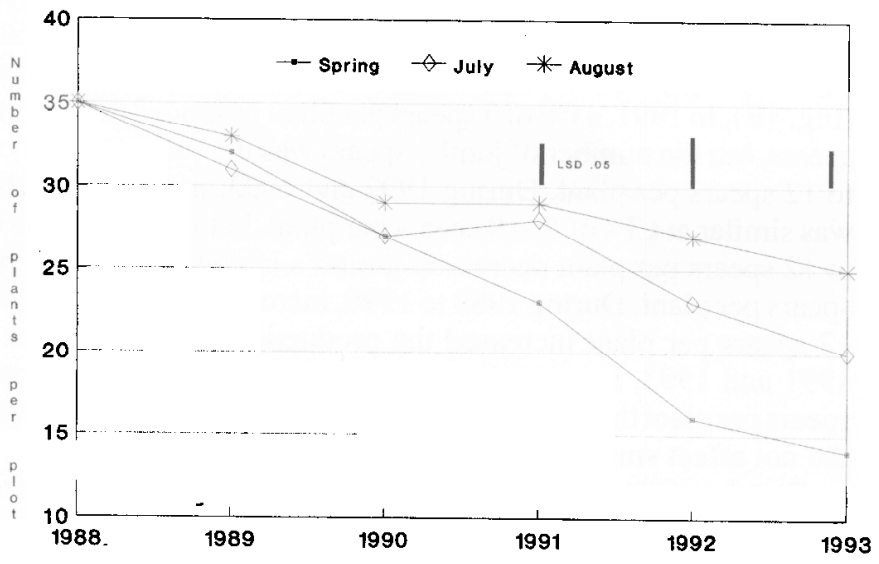

Fig. 6. Influence of harvest time on plant stand per plot from 1989 to 1993 . Mean separation is within each year and are significant by LSD, $P=0.05$.

5 harvest years; however, cumulative losses due to $\mathrm{CP}$ averaged over the 5 years were significant. From 1989 to 1993, 36\% stand loss occurred in spring-and summer-harvested plots at a $\mathrm{CP}$ of 3 spears per plant, but about $46 \%$ for CPS from 6 to 12 spears per plant.

Treatment effects on the plants' ability to reach a prescribed $C P$. Each cutting pressure treatment (ranging from as few as 3 per plant to as high as 12 spears per plant) prescribed a certain number of spears to be harvested before the termination of the harvest season. Yearly repetition of these different cutting pressures in some years reduced the ability of a plant to reach the prescribed $\mathrm{CP}$ treatment level before the end of the harvest season. The inability of a plant to produce the prescribed $\mathrm{CP}$ treatment level before the tertnina-

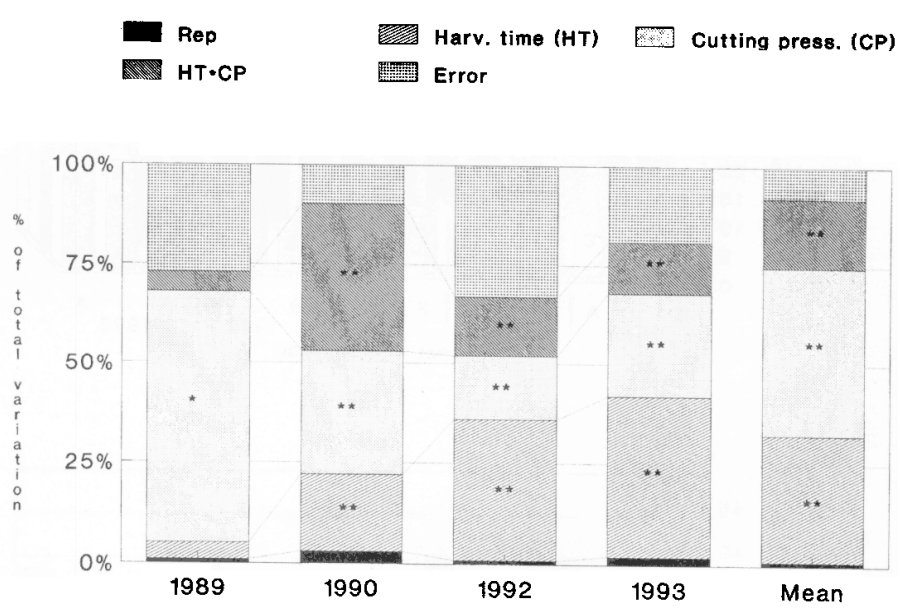

Fig. 7. Total variation from 1989 to 1993 on the percent of plants that did not reach cutting pressure treatment levels before termination of the harvest season (30 harvests) due to sources of variation in the ANOVA. Sum of squares for each factor converted to a percentage of total sum of squares and $\mathrm{F}$ test significant at $P=0.05(*)$ and $0.01(* *)$.

tion of the harvest season indicated dwindling vigor affecting recovery and yield.

In 1989 and 1990, the main effect of CP contributed 63\% and $31 \%$, respectively, of all the variation in this variable (Fig. 7). From 1992 to 1993, however, the main effect of HT became the dominant treatment effect contributing $35 \%$ and $40 \%$ variation, respectively,vs. only $16 \%$ and $26 \%$ for the main effect of $\mathrm{CP}$. Summation of the total effect over all harvest years indicated that CP had a greater effect on a plants' ability to reach CP than HT. 


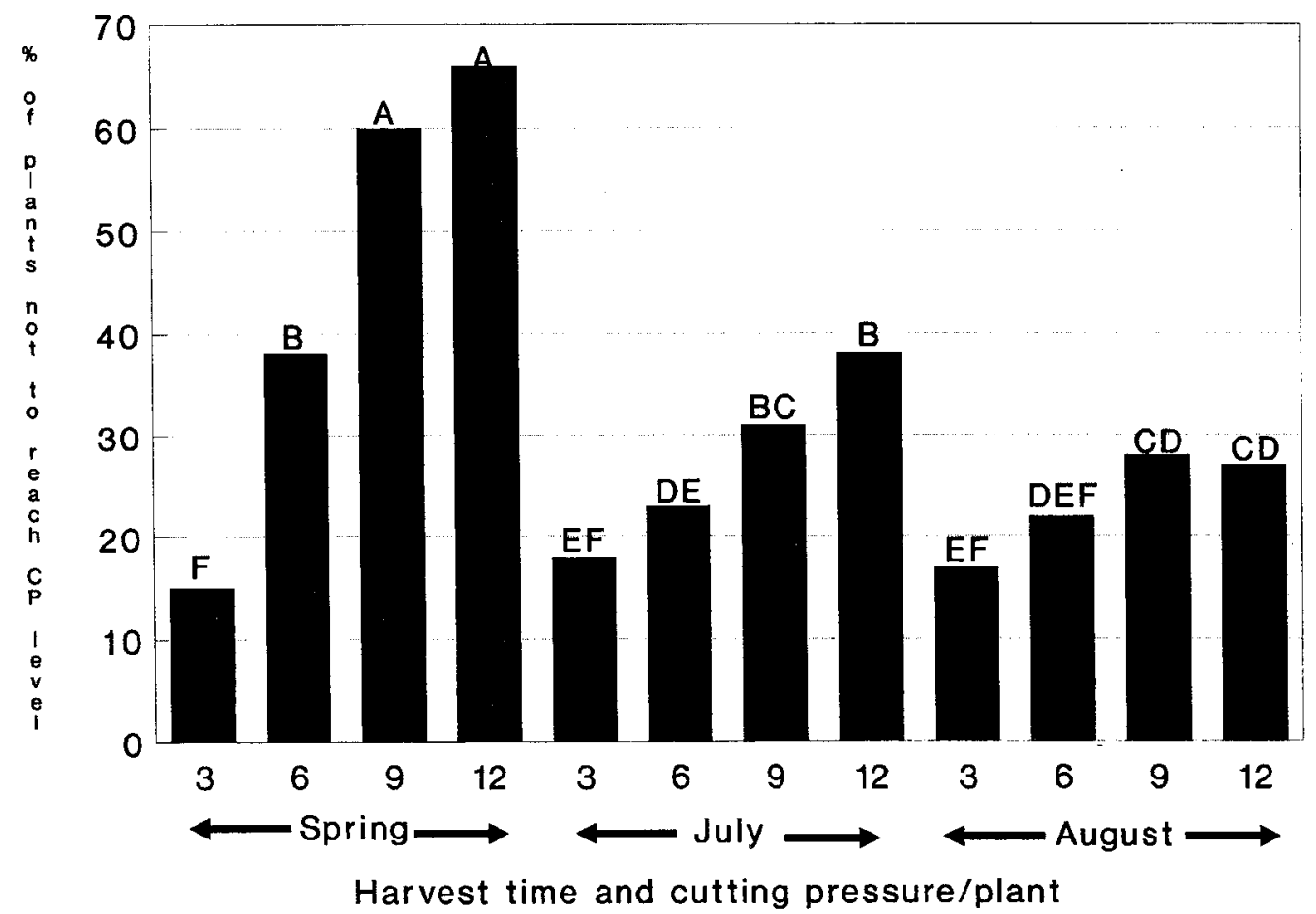

Fig. 8. Influence of cutting pressure and harvest time on the percent of plants that did not reach cutting pressure treatment levels before termination of the harvest (30 harvests) from 1989 to 1993 . Bars with different letters are significant by LSD, $P=0.05$.

The effect of CP on the plants' ability to reach CP levels interacted with HT in each harvest year, but the overall mean of this variable from 1989 to 1993 illustrated the general trends of this interaction (Fig. 8). In spring, as CP increased from 3 to 9 spears, significantly fewer plants reached $\mathrm{CP}$ within the time limit of 30 harvests/plot. Increasing the $\mathrm{CP}$ to 12 spears per plant did not affect the plants' ability to reach $\mathrm{CP}$ any more than at a $\mathrm{CP}$ of 9 spears per plant. During summer forcing in July and August, more plants reached $\mathrm{CP}$ treatment levels even at the highest $\mathrm{CP}$ than in the spring. Cooler temperatures during spring slowed spear emergence while warmer summer temperatures accelerated emergence in July and August. During July, as CP increased from 3 to 9 spears, fewer plants reached $\mathrm{CP}$ treatment levels before harvest termination. The maximum percent of plants that did not reach CP in July, was about $36 \%$ for CPS of 9 to 12 spears per plant in contrast to about $64 \%$ for the same CPS in spring. The effect of forcing in July and August at CPS of 3 to 6 spears per plant were similar, but more plants reached CP levels during August at 12 spears per plant than at the same CP in July.

\section{Discussion}

In coastal South Carolina, the productive lifespan of springharvested ' $\mathrm{UC} 157 \mathrm{~F}_{1}$ ' asparagus lasted 3 years with poor performance in the fourth and fifth harvest years. In contrast, Augustforced ' $\mathrm{UC} 157 \mathrm{~F}_{1}$ ' asparagus produced acceptable yields throughout the five-year period. This outcome agrees with previous reports (Dufault, 1994a and 1994b). First spring spear emergence in coastal South Carolina occurs $\approx 15$ Feb. (Dufault, 1994b) with the harvest season terminating in mid-April. Natural fern senescence does not begin until late November. Therefore, the average lifespan of fern produced after spring harvests is about 7 months. Hung (1980) reported that asparagus fern reaches highest levels of photosynthetic efficiency about 3 months after emerging, but declines to low levels after 5 months. In the present study, it is suggested that by midsummer, the spring ferns' capacity to synthesize carbohydrates may have been reduced and the plants utilized stored crown carbohydrates. Yearly repetition of these stresses by 1992 reduced plant stand, vigor and yield in contrast to summer-forced plots. Even $\mathrm{CP}$ severity in spring as low as 3 spears per plant did not ameliorate stand and yield depressions. Removal of inefficient fern during summer forcing may have enabled summer-forced asparagus to recover more successfully, tolerate harvest stresses better and live longer in contrast to spring-harvested asparagus. Dufault (1994a) reported higher crown carbohydrate levels with July-and August-forced plants in contrast to spring harvesting. In the present study, asparagus forced in July yielded acceptably for the first 3 years, but production declined in the fourth and fifth year. Stand loss in July-forced plots accelerated by the fourth harvest year with fewer plants contributing to yields. Asparagus forced in July at a $\mathrm{CP}$ of 12 spears per plant produced the greatest yields of all for the first 2 harvest years, but for the last 3 harvest years, forcing at a $\mathrm{CP}$ of 9 spears per plant produced higher yields.

August forcing continued to produce excellent yields throughout the five harvest years. Forcing in August yielded similarly as July forcing in 3 out of 4 harvest years from 1989 to 1992. In 1993, forcing in August at 9 spears per plant produced the greatest yields which were $\approx 60 \%$ higher than the previous year. The long-term acceptable performance with August forcing may be a result of having the lowest plant loss of all over the experimental period. Although ' $\mathrm{UC} 157 \mathrm{~F}_{1}$ ' asparagus was not suited for spring production in this region, this variety performed acceptably when summer forced. Since August forcing yielded consistently for 5 years at high CPS with less stand loss than July forcing, forcing in August has potential value for commercial adaptation in coastal South Carolina. 


\section{Literature Cited}

Brasher, E P. 1956. Effects of spring, summer, and fall cutting of asparagus on yield and spear weight. Proc. Amer. Soc. Hort. Sci. 67:377-383.

Campbell Institute for Agricultural Research 1970. Twice-a-year harvesting of asparagus. HortScience 5:512.

Cook, W. 1986. Asparagus weed and disease control. Agricultural chemicals handbook. Clemson Univ. Coop. Ext. Serv. EC 670.

Deonier, M. and G. Hoffman. 1944. Asparagus production in the lower south with special reference to time and length of cutting season. Proc. Amer. Soc. Hort. Sci. 45:413-417.

Dufault, R. 1994a. Impact of forcing summer asparagus in coastal South Carolina on yield, quality and recovery from harvest pressure. J. Amer. Soc. Hort. Sci. 119:396-402.

Dufault, R.J. 1994b. Relationship between soil temperatures and spring asparagus spear emergence in coastal South Carolina. Acts Hort. (In press.)

Farish, L.R. 1937. Fall cuttings of asparagus compared with spring cuttings under Mississippi conditions. Proc. Amer. Soc. Hort. Sci. 35:693-695.

Haber. E. 1935. Effect of harvesting, spacing, and age of plants on yields of asparagus. Iowa Agr. Expt. Sta. Bul. 339:116.

Hung, L. 1980. Special aspect of asparagus growing in Taiwan. Chinese Soc. Hort. Sci. 26:1-10.

Jasmin, J. and J. Laliberte. 1962. Note on fall cutting of asparagus on organic soils in southwestern Quebec. Can. J. Pit. Sci. 42:737-738.

Jones, H. 1932. Effect of extending the cutting season on the yield of asparagus. California Agr. Expt. Sta. Bul. 535.

Scott, L., J. Mitchell, and R. McGinty. 1939. Effects of certain treatments on the carbohydrate reserves of asparagus crowns. South Carolina Agn. Expt. Stn. Bul. 321.

Shelton, D. and M. Lacy. 1980. Effect of harvest duration on yield and on depletion of storage carbohydrates in asparagus roots. J. Amer. Soc. Hort. Sci. 105:332-335.

Takatori, F., J. Stillman and F. Souther. 1970. Asparagus yields and plant vigor as influenced by time and duration of cutting. California Agri. 24:9-11.

U.S. Department of Agriculture. 1977. United States standards for grades of fresh asparagus. U.S. Dept. of Agr. Food Safety and Quality Serv., Washington, D.C.

Williams, J. and J. Garthwaite. 1973. The effects of seed and crown size and length of cutting period on the yield and quality of asparagus grown on ridges. Expt. Hort. 25:77-86. 